\title{
Petrologia de nova ocorrência dos Anfibolitos Alto Alegre, SE do Cinturão Dom Feliciano, Brasil
}

\author{
Rodrigo Chaves RAMOS', Edinei KOESTER² \& Daniel Triboli VIEIRA ${ }^{3}$
}

\begin{abstract}
1 Secretaria de Meio Ambiente e Preservação Ecológica, Prefeitura Municipal de Sapiranga. Av. João Corrêa, 808, CEP 93.800-222, Sapiranga, RS, Brasil (rodrigoramos@sapiranga.rs.gov.br).

2 Departamento de Geologia, Instituto de Geociências, Universidade Federal do Rio Grande do Sul. Caixa Postal 15001, CEP 91.501-970, Porto Alegre, RS, Brasil (koester@ufrgs.br).

${ }^{3}$ Programa de Pós-graduação em Geociências, Instituto de Geociências, Universidade Federal do Rio Grande do Sul. Av. Bento Gonçalves, 9.500, CEP 91.540-000, Porto Alegre, RS, Brasil (danieltriboli@hotmail.com).
\end{abstract}

\begin{abstract}
Resumo. Na região de Herval, extremo sul do setor brasileiro do Cinturão Dom Feliciano, foram encontradas novas ocorrências dos Anfibolitos Alto Alegre. Esses anfibolitos ocorrem como xenólitos em granitoides de ca. 630-610 Ma da suíte intrusiva Pinheiro Machado, que são as rochas predominantes na região. 0 presente artigo apresenta um estudo integrado de petrografia (microscopia óptica) e geoquímica de rocha total (elementos maiores, traços e ETR) e isotópica (Sr-Nd), em uma amostra representativa dos Anfibolitos Alto Alegre, com o objetivo de aprofundar o entendimento sobre esta unidade e sua petrogênese. A amostra apresenta mineralogia constituída por hornblenda $( \pm 60 \%)$, plagioclásio $( \pm 20 \%)$, biotita $( \pm 10$ $\%)$, epidoto ( $\pm 5 \%)$, quartzo (<5\%) e, subordinadamente, titanita, clorita, rutilo, pirita e apatita. A textura principal é a granoblástica poligonal, marcada por hornblenda + plagioclásio, indicando equilíbrio metamórfico em ca. $600^{\circ} \mathrm{C}$ e pico metamórfico em condições de fácies anfibolito. A geoquímica de rocha total sugere um protólito gabroico oceânico. Razões de elementos traços e ETR sugerem um ambiente de suprassubducção, transicional entre MORB e IAB, cuja fonte mantélica foi contaminada por componentes crustais. A assinatura isotópica Sr-Nd fortalece essa hipótese $\left({ }^{87} \mathrm{Sr} /{ }^{86} \mathrm{Sr}_{(t)}=0,707 ;{ }^{147} \mathrm{Sm} /{ }^{144} \mathrm{Nd}=0,118 ; \varepsilon \mathrm{Nd}_{(t)}=-7,5\right)$. A partir dos resultados e da comparação com metamafitos oceânicos da região, sugere-se que os Anfibolitos Alto Alegre poderiam representar relictos do paleo-oceano Adamastor Sul, relacionado ao paleocontinente Gondwana Ocidental.
\end{abstract}

Palavras-chave. Petrografia, geoquímica, isótopos, petrogênese, Terreno Pelotas.

\begin{abstract}
Petrology of a NeW occurrence of Alto Alegre Amphibolites, SE Dom Feliciano BELT, BRAZIL. In the Herval region, southernmost Brazilian sector of the Dom Feliciano Belt, new occurrences of the Alto Alegre Amphibolites were found. These amphibolites occur as xenoliths in granitoids of the ca. 630-610 Ma Pinheiro Machado intrusive suite, which are the predominant rocks of the region. The present paper presents an integrated study of petrography (optical microscopy), whole rock geochemistry (major, trace and REE) and whole rock isotope geochemistry (Sr-Nd) on a representative sample of the Alto Alegre Amphibolites, aiming to deepen the understanding about this unit and its petrogenesis. The sample presents a mineralogy constituted by hornblende $( \pm 60 \%)$, plagioclase $( \pm 20 \%)$, biotite $( \pm 10 \%)$, epidote $( \pm 5$ $\%)$, quartz $(<5 \%)$, and minor titanite, chlorite, rutile, pyrite, and apatite. Hornblende + plagioclase mark the granoblastic polygonal texture, suggesting metamorphic equilibrium at ca. $600^{\circ} \mathrm{C}$ and peak metamorphism at amphibolite facies conditions. The whole rock geochemistry suggests an oceanic gabbroic protolith. Trace and REE ratios suggest a suprasubduction environment, transitional between MORB and IAB, whose mantle source was contaminated by crustal components. The $\mathrm{Sr}-\mathrm{Nd}$ isotopic signature strengthen this hypothesis $\left({ }^{87} \mathrm{Sr} /{ }^{86} \mathrm{Sr} r_{(t)}=0.707\right.$; $\left.{ }^{147} \mathrm{Sm} /{ }^{144} \mathrm{Nd}=0.118 ; \varepsilon \mathrm{Nd}_{(\mathrm{t})}=-7,5\right)$. From the results and the comparison with oceanic metamafites found in the region, this paper suggests that the Alto Alegre Amphibolites could represent relicts of the South Adamastor paleo-ocean, related to the West Gondwana paleocontinent.
\end{abstract}

Keywords. Petrography, geochemistry, isotopes, petrogenesis, Pelotas Terrane. 


\section{Introdução}

No setor sul da porção brasileira do Cinturão Dom Feliciano, no Escudo Sul-rio-grandense, são encontradas extensas áreas graníticas neoproterozoicas associadas ao Terreno Cuchilla Dionisio-Pelotas, um dos terrenos relacionados à amalgamação do paleocontinente Gondwana Ocidental durante os estágios intermediários e finais do ciclo orogênico Brasiliano-Pan-africano (e.g., Bossi \& Gaucher, 2004; Silva et al., 2005a; Hueck et al., 2018). Esse terreno é constituído por batólitos multi-intrusivos e polifásicos, agrupados em suítes intrusivas com características petrográficas, geoquímicas e geocronológicas em comum (e.g., Fragoso-César et al., 1986; Philipp, 1998; Hueck et al., 2018). Nas suítes intrusivas mais antigas, como a denominada Pinheiro Machado (Philipp, 1998), é comum a presença de xenólitos e roof pendants metamórficos para- e ortoderivados centimétricos a decamétricos, os quais representam crosta continental e oceânica pretérita (e.g., Philipp \& Machado, 2002; Ramos \& Koester, 2014; Vieira et al., 2019).

Algumas dessas ocorrências de xenólitos e roofpendants foramagrupadas nos denominados "septos do embasamento das suítes graníticas do Batólito Pelotas" (Fragoso-César et al., 1986; Philipp, 1998; Philipp \& Machado, 2002). Entre essas, foram descritas ocorrências de anfibolitos ortoderivados, denominados de Anfibolitos Alto Alegre (Philipp, 1998; Philipp \& Machado, 2002), localizados a leste do município de Herval. Esses anfibolitos, no entanto, foram investigados apenas em trabalhos de cunho regional, com ênfase em petrografia (Philipp, 1998; Philipp \& Machado, 2002).

Dessa maneira, o presente trabalho tem o objetivo de investigar a gênese e evolução dos Anfibolitos Alto Alegre, apresentando um estudo integrado de petrografia (microscopia óptica) e geoquímica de rocha total (elementos maiores, traços e terras raras) e isotópica ( $\mathrm{Sr}-\mathrm{Nd}$ em rocha total), em uma amostra representativa desses anfibolitos. Os resultados obtidos são comparados com os de ocorrências similares encontradas no extremo sul do Escudo Sulrio-grandense, buscando inserir os Anfibolitos Alto Alegre no contexto evolutivo do Cinturão
Dom Feliciano e do paleocontinente Gondwana Ocidental.

\section{Contexto geológico}

Os Anfibolitos Alto Alegre estão localizados no município de Herval, estado do Rio Grande do Sul, nas proximidades das nascentes dos arroios Guarapepi e Divisa, próximo à rodovia RS-473 entre Herval e a localidade de Vila Airosa Galvão. Essa região está localizada no extremo sul da porção brasileira do Cinturão Dom Feliciano (Fig. 1A), faixa móvel que se estende desde o leste do estado de Santa Catarina até o extremo sudeste do Uruguai, a qual representa o setor meridional da Província Mantiqueira (Almeida et al., 1981; Silva et al., 2005a). Essa província, juntamente com sua contraparte africana (Orógeno Damara, no oeste da Namíbia - e.g., Gray et al., 2008), está relacionada à configuração do paleocontinente Gondwana Ocidental durante o ciclo orogênico Brasiliano-Pan-africano (e.g., Gaucher et al., 2009; Siegesmund et al., 2018).

No Escudo Sul-rio-grandense o Cinturão Dom Feliciano é comumente subdividido em três (Fernandes et al., 1995a, 1995b; Costa, 1997) ou quatro domínios geofísicos principais (Ramos et al., 2014), englobando associações petrotectônicas brasiliano-panafricanas distintas: Domínio Oeste (Terreno São Gabriel - e.g., Hartmann et al., 2007), Domínio Central (Terreno Tijucas e Bacia do Camaquã - e.g., Chemale Jr. et al., 1995), Domínio Leste (Terreno Cuchilla Dionisio-Pelotas - e.g., Fragoso-César et al., 1986; Philipp, 1998; Bossi \& Gaucher, 2004), e Domínio Sudeste (Terreno Punta del Este, sensu Ramos et al., 2018) (Fig. 1A).

Esses terrenos, com distintas evoluções crustais, refletem a complexa história geológica do Cinturão Dom Feliciano, que pode ser dividida em três estágios orogênicos principais (Babinski et al., 1997; Silva et al., 2005a, 2005b; Saalmann et al., 2011; Brito-Neves et al., 2014; Hueck et al., 2018; Vieira, 2020; Ramos et al., 2020): Brasiliano I, com clímax em ca. 730-700 Ma, relacionado às orogenias São Gabriel (Domínio Oeste) e Piratini (Domínio Leste) e ao encerramento do paleo-oceano Charrua; Brasiliano II, com 


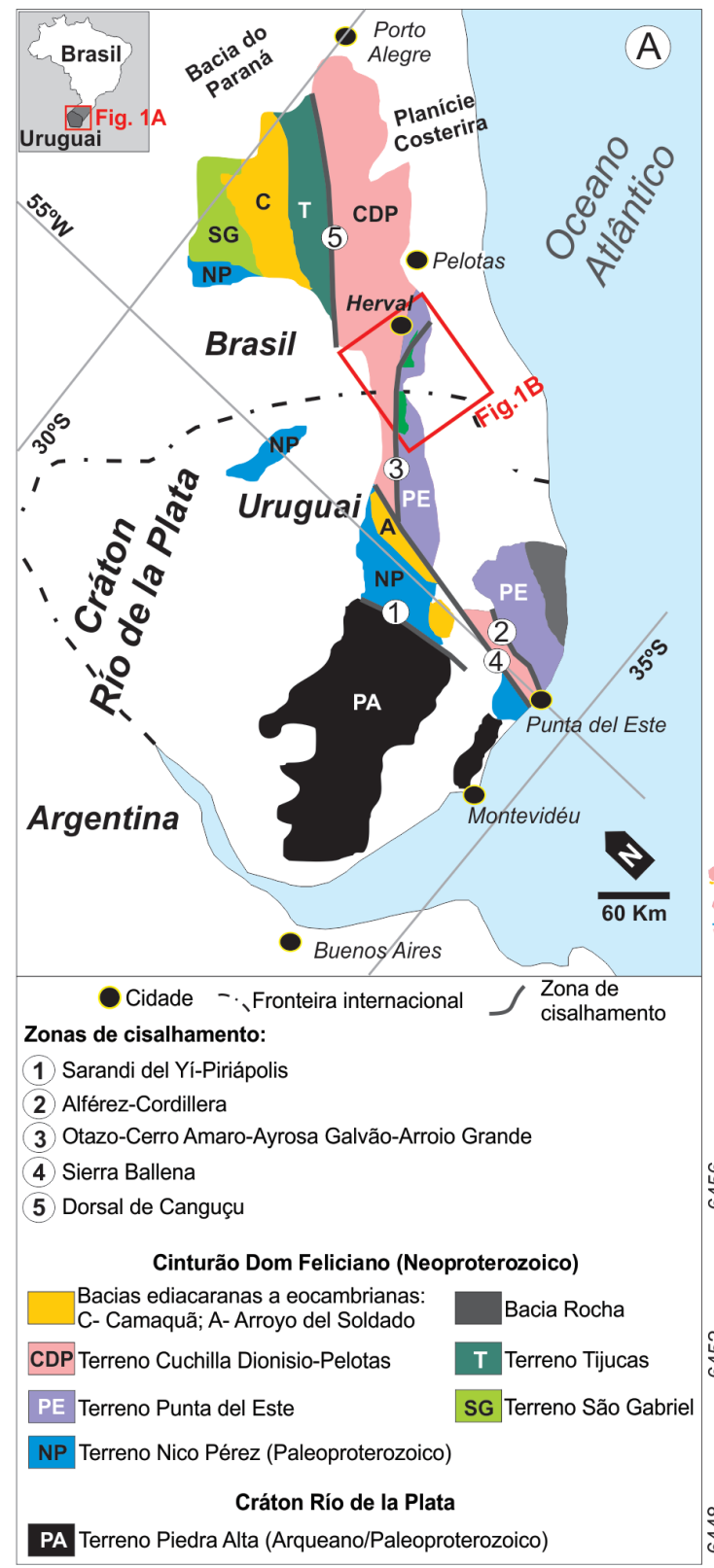

B
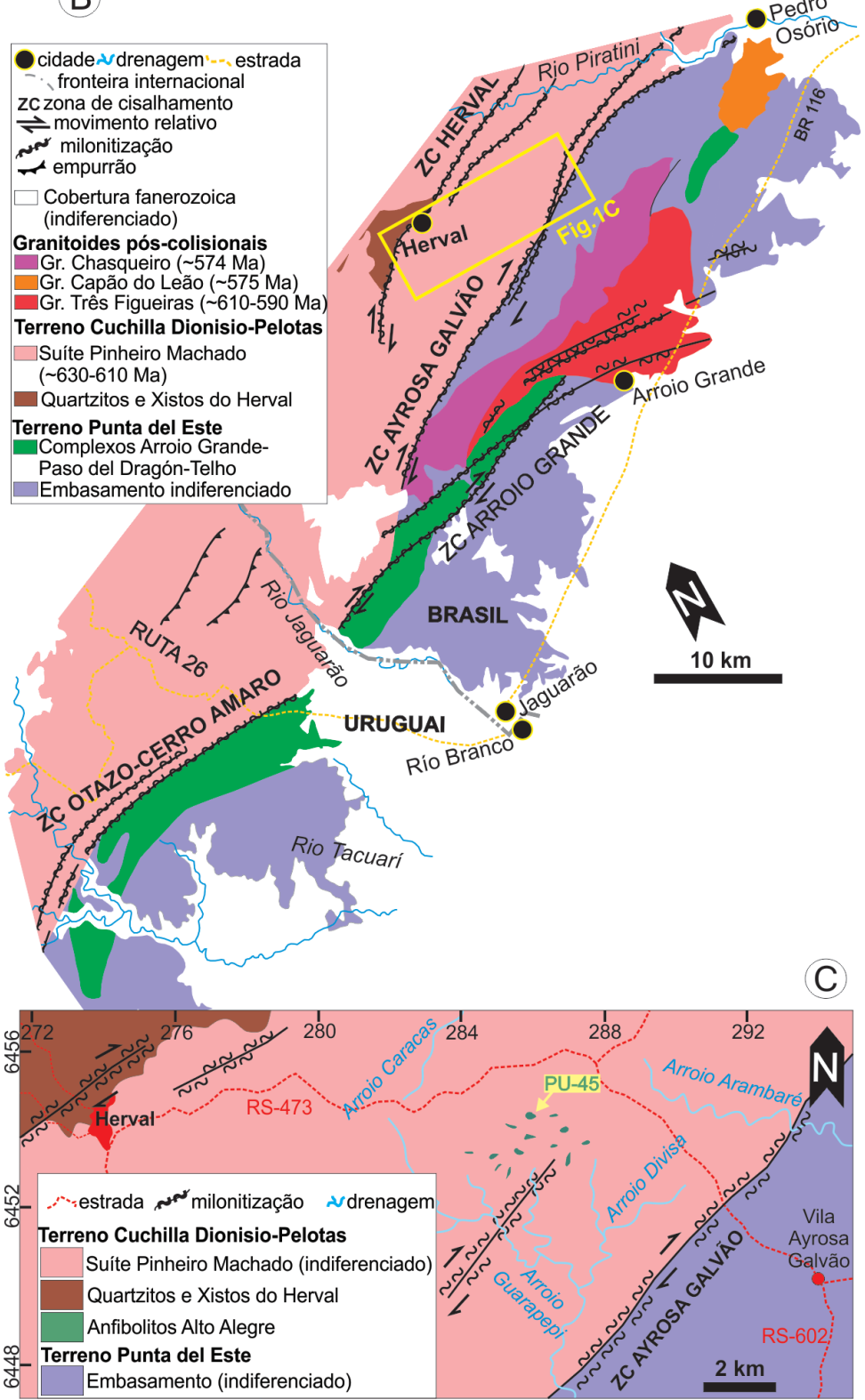

Figura 1. Mapas geológicos simplificados e localização da área de estudo. A) Localização da região de Herval, no contexto do Cinturão Dom Feliciano (modificado de Blanco et al., 2011, e Ramos et al., 2019); B) Geologia simplificada do extremo sul do setor brasileiro e extremo nordeste do setor uruguaio do Cinturão Dom Feliciano (modificado de Ramos et al., 2018); C) Geologia simplificada da área-tipo dos Anfibolitos Alto Alegre e localização da amostra estudada (PU-45). Figure 1. Simplified geologic maps and location of the study area. A) Location of the Herval region, in the context of the Dom Feliciano Belt (modified from Blanco et al., 2011, and Ramos et al., 2019); B) Simplified geology of the southernmost Brazilian sector and northeasternmost Uruguayan sector of the Dom Feliciano Belt (modified from Ramos et al., 2018); C) Simplified geology of the type-area of the Alto Alegre Amphibolites and location of the studied sample (PU-45).

clímax em ca. 640-620 Ma, relacionado à orogenia Dom Feliciano nos domínios Central, Leste e Sudeste, representado por intenso magmatismo continental e retrabalhamento crustal, e o encerramento do Oceano Adamastor Sul; Brasiliano III, entre ca. 595-560 Ma, com geração de magmatismo granítico relacionado aos eventos colisionais finais do ciclo orogênico Brasiliano-Pan-africano.

Os Anfibolitos Alto Alegre, foco deste estudo, ocorrem como xenólitos em granitoides do Terreno Cuchilla Dionisio-Pelotas, o qual se estende de Porto Alegre até Jaguarão, fronteira com o Uruguai, na área a leste da Zona de Cisalhamento Dorsal de Canguçu e Sutura de Porto Alegre (e.g., Fernandes et al., 1995a, 1995b; Costa, 1997). Esse terreno neoproterozoico é constituído majoritariamente por granitoides do denominado Batólito Pelotas (FragosoCésar et al., 1986), um complexo de batólitos 
multi-intrusivos e polifásicos de composição diorítica a granítica relacionados aos eventos Brasiliano II e III de Silva et al. (2005a). Também são encontrados fragmentos/xenólitos/roof pendants metamórficos para- e ortoderivados, métricos a quilométricos, denominados genericamente de Septos do Embasamento (Fragoso-César et al., 1986; Philipp, 1998; Philipp \& Machado, 2002). Uma dessas unidades metamórficas são os Anfibolitos Alto Alegre.

Na região de Herval (Fig. 1B e 1C), onde afloram os Anfibolitos Alto Alegre, predominam unidades da suíte intrusiva Pinheiro Machado, a mais antiga das suítes graníticas que constituem o Terreno Cuchilla Dionisio-Pelotas (Philipp, 1998), representando cerca de $30 \%$ de sua área. Esses granitoides apresentam composição granodiorítica a monzogranítica, subordinadamente tonalítica e diorítica/quartzodiorítica, com assinatura geoquímica cálcicoalcalina médio a alto- $K$, interpretada como de ambiente de arco magmático continental relacionado à subducção (e.g., FragosoCésar, 1991; Frantz \& Nardi, 1992; Fernandes et al., 1995a; Philipp, 1998; Silva et al., 2005b), com idades magmáticas entre 630-610 Ma (Babinski et al., 1997; Philipp et al., 2016). Dentre os denominados Septos do Embasamento encontrados em granitoides da suíte intrusiva Pinheiro Machado, destacam-se, na região próxima à zona urbana de Herval, os Quartzitos e Xistos do Herval (Fragoso-César et al., 1986), que constituem um corpo quilométrico composto por xistos metassedimentares de baixo grau, de composição pelítica, intercalados com lentes de quartzito. Também são encontrados, a leste, os Anfibolitos Alto Alegre, foco do presente estudo (Fig. 1C).

Os Anfibolitos Alto Alegre foram descritos pela primeira vez em Philipp (1998), que estudou anfibolitos que afloram próximos à rodovia RS-473, na região das nascentes do arroio Guarapepi (Fig. 1B). Segundo Philipp (1998), os anfibolitos ocorrem como xenólitos centimétricos a métricos, angulosos a subangulosos a subarredondados, com contatos bem definidos (localmente gradacionais) e limites retos, localmente difusos. As relações de contato indicam pouca assimilação pelo magma granítico. A desestabilização dos anfibolitos por reação com o magma é marcada por schlierens e outros agregados máficos irregulares. Processos de assimilação podem ter causado modificação química do granito, evidenciados pela presença de anfibólio nos granitos encaixantes (Philipp, 1998).

Conforme Philipp (1998), a composição mineralógica dos Anfibolitos Alto Alegre constituída essencialmente por hornblenda e plagioclásio (subordinadamente diopsídio), variando entre termos ricos em hornblenda, ricos em plagioclásio, e intermediários entre esses minerais, sugerem protólitos do tipo piroxenito ou melagabro. A paragênese hornblenda + plagioclásio + diopsídio, em conjunto com a ausência de estruturas e texturas orientadas, sugere metamorfismo termal de fácies hornblenda cornubianito (Philipp, 1998).

\section{Métodos}

Para o presente estudo foi selecionada uma amostra representativa de xenólito dos Anfibolitos Alto Alegre (amostra PU-45), coletada na área-tipo dessa unidade, próximo às nascentes dos arroios Guarapepi e Divisa a leste do município de Herval (local da coleta da amostra marcado na Fig. 1C). Para o estudo petrográfico foi feita uma lâmina delgada polida, preparada no Laboratório de Laminação e Polimento, do Núcleo de Preparação de Amostras (NPA), Centro de Estudos em Petrologia e Geoquímica (CPGq), Instituto de Geociências (IGEO) da Universidade Federal do Rio Grande do Sul (UFRGS). Para o estudo geoquímico e isotópico a amostra foi cominuída a < 200 mesh no Laboratório de Cominuição de Rocha do NPA-CPGq-IGEOUFRGS, com o auxílio de prensa hidráulica e moinho de ágata.

Para as análises geoquímicas de rocha total, a amostra cominuída foi enviada ao Acme Analytical Laboratories Ltd. (Canadá). Os elementos maiores e traços foram analisados por Espectrometria de Emissão Óptica com Plasma (ICP-OES), e os elementos terras raras (ETR) foram analisados por Espectrometria de Massa com Fonte de Plasma (ICP-MS). A perda ao fogo (LOI) foi determinada a $1000{ }^{\circ} \mathrm{C}$ por $60 \mathrm{~min}$. 

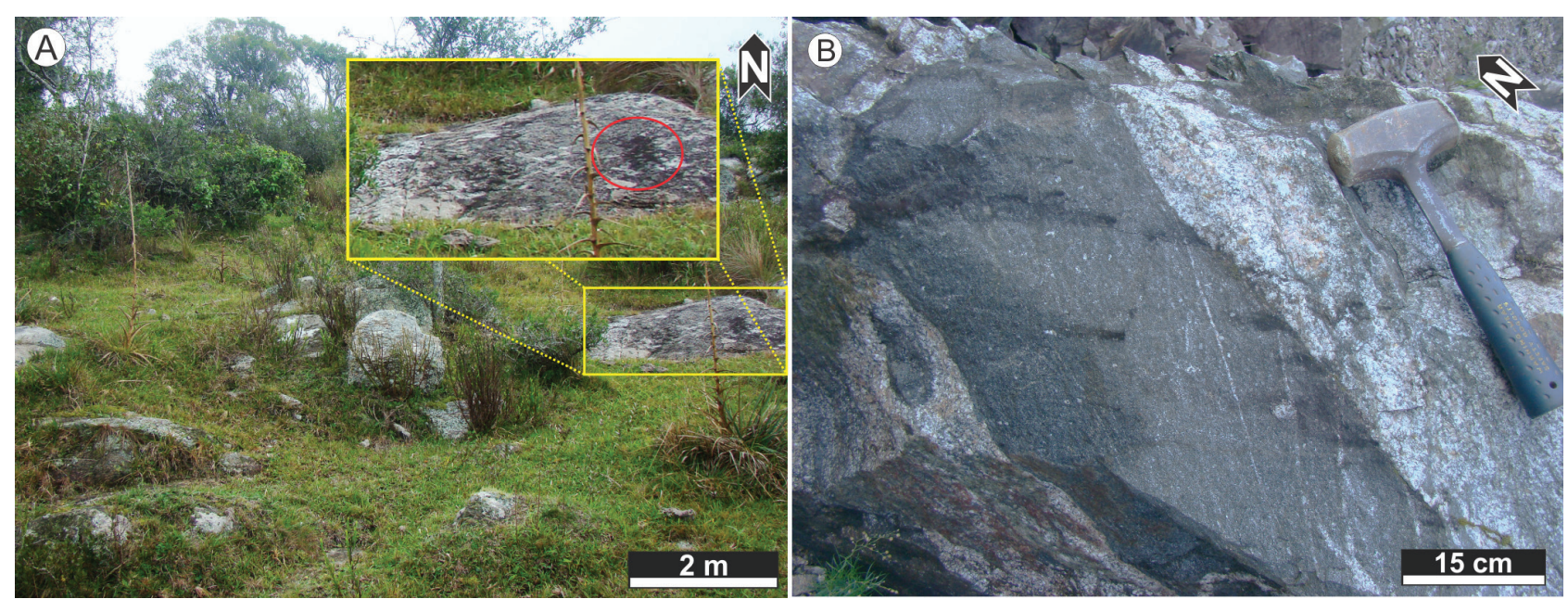

Figura 2. Aspectos de campo da área-tipo dos Anfibolitos Alto Alegre. A) Campo de matacões de granitoides indiferenciados da suíte intrusiva Pinheiro Machado, nos quais os Anfibolitos Alto Alegre ocorrem como xenólitos (marcado com círculo vermelho); B) Detalhe de xenólitos de anfibolito (escuro) em um granitoide da suíte intrusiva Pinheiro Machado (claro) (plano XY).

Figure 2. Field aspects of the type-area of the Alto Alegre Amphibolites. A) Boulders of undifferentiated granitoids from the Pinheiro Machado intrusive suite, in which the Alto Alegre Amphibolites occur as xenoliths (marked in red circle); B) Detail of amphibolite xenoliths (dark) in a Pinheiro Machado granitoid (light) (XY plane).

Para as análises isotópicas de $\mathrm{Sr}-\mathrm{Nd}$, as amostras cominuídas foram preparadas e analisadas no Laboratório de Geologia Isotópica (CPGq-IGEO-UFRGS). Para o sistema Sm-Nd, a amostra foi lavada em 2,5 $\mathrm{N} \mathrm{HCl}$, e posteriormente foi adicionado traçador com ${ }^{149} \mathrm{Sm} /{ }^{150} \mathrm{Nd}$. Após, a amostra foi completamente dissolvida em HF, $\mathrm{HNO}_{3}$ e $\mathrm{HCl}$ concentrados. Resina aniônica LNB50-A (100-150 m) foi usada para a separação de $\mathrm{Sm}$ e $\mathrm{Nd}$. Cada elemento foi coletado e a amostra foi secada e adicionada, com 0,25 $\mathrm{N} \mathrm{H}_{3} \mathrm{PO}_{4}$, a um filamento simples de $\mathrm{Ta}$ (para $\mathrm{Sm}$ ) e a um filamento triplo de Ta-Re-Ta (para $\mathrm{Nd)}$ ). A amostra foi lida em um espectrômetro de massas por ionização térmica multicoletor VG Sector 54, em modo estático. As razões de $\mathrm{Nd}$ foram normalizadas a ${ }^{146} \mathrm{Nd} /{ }^{144} \mathrm{Nd}=0,7219$. O valor padrão de ${ }^{143} \mathrm{Nd} /{ }^{144} \mathrm{Nd}$ usado (padrão de referência $\mathrm{Nd}_{2} \mathrm{O}_{3}$ LaJolla) foi de 0,511859 \pm 0,000010 . O erro padrão para ${ }^{147} \mathrm{Sm} /{ }^{144} \mathrm{Nd}$ foi de $\pm 1 \%$ ou menor, baseado em análise interativa e recalibração de traçador, e $<0,0057 \%$ para a razão ${ }^{143} \mathrm{Nd} /{ }^{144} \mathrm{Nd}$. O valor de branco foi menor que $60 \mathrm{pg}$ para $\mathrm{Nd}$. $\mathrm{O}$ número total de análises foi de 100.

Para o sistema Rb-Sr, a amostra cominuída foi dissolvida em $\mathrm{HF}$ e $\mathrm{HNO}_{3}$ concentrados. $\mathrm{O} \mathrm{Rb}$ e o $\mathrm{Sr}$ foram separados em colunas catiônicas contendo resina catiônica AG-50W-X8. As análises foram realizadas no mesmo laboratório, também com o espectrômetro VG Sector 54. Os resultados foram calibrados usando o padrão de referência NBS-987 ( $\mathrm{SrCO}_{3} \mathrm{com}$ razão média de ${ }^{87} \mathrm{Sr} /{ }^{86} \mathrm{Sr}$ de 0,71026 $\left.\pm 0,000014\right)$. O valor de branco foi menor que 150 pg para Sr. O número total de análises foi de 120.

Todos os dados de geoquímica de rocha total e geoquímica isotópica foram tratados com o auxílio do programa GCDKit (Janoušek et al., 2006). Abreviações usadas para as discussões geoquímicas e isotópicas: $\mathrm{MORB}=$ basalto de dorsal meso-oceânica; $\mathrm{BABB}=$ basalto de retroarco; $\mid A B=$ basalto de arco insular; $W P B=$ basalto de intraplaca.

\section{Resultados e discussões}

\section{1 Microscopia óptica}

Macroscopicamente, a amostra estudada apresenta coloração verde acinzentado. O contato com o granitoide encaixante é reto e sem evidência de reações, como o mostrado na figura 2B. A olho nu se identifica anfibólio, plagioclásio, biotita, quartzo e pirita, com granulação fina a média. Porções cloritizadas marcam alteração da rocha. Sua estrutura é predominantemente maciça, com foliação incipiente (Fig. 3A). A 
textura dominante é granoblástica, localmente lepidoblástica em áreas onde predomina biotita.

Ao microscópio se identifica mineralogia constituída por anfibólios verdes e beges a nicóis descruzados ( $\pm 60 \%$ ) - aqui denominados genericamente de hornblenda -, plagioclásio $( \pm$ $20 \%$ ), biotita ( $\pm 10 \%)$, epidoto ( $\pm 5 \%)$, quartzo $(<5$ $\%)$, e proporções subordinadas de titanita, clorita, rutilo, pirita e apatita.

A hornblenda e o plagioclásio apresentam granulação fina a média. Os cristais finos variam de anédricos a subédricos. Os cristais médios de ambos estão em sua maioria recristalizados, constituindo a textura granoblástica poligonal dominante da amostra (Fig. 3B) a qual, localmente, apresenta foliação incipiente (Fig 3C e 3D). Epidotização é comum nos cristais de hornblenda (Fig. 3C) e plagioclásio (Fig. 3E). Neste último, é também comum a sericitização.

A biotita apresenta granulação fina a média, com cristais anédricos a subédricos. Em geral apresenta textura decussada, localmente lepidoblástica (Fig. 3D). Os cristais de biotita estão, em sua maioria, associados aos de hornblenda (Fig. 3E), sendo possivelmente seus subprodutos de alteração e/ou retrometamorfismo. A biotita, por sua vez, altera-se para epidoto (Fig. 3E) e clorita (Fig. 3D e 3F). Localmente, observa-se formação de rutilo a expensas de biotita (Fig. 3F).

O quartzo é anédrico, intersticial, com granulação fina a média. Os cristais, em sua maioria, exibem extinção ondulante. A titanita ocorre disseminada pela amostra. Apresenta granulação muito fina a fina, com cristais anédricos a euédricos. Ocorre associada à hornblenda, biotita e epidoto, podendo, dessa maneira, ser oriunda da desestabilização desses minerais.

$\mathrm{Na}$ amostra estudada a paragênese hornblenda + plagioclásio define o pico metamórfico em condições de fácies anfibolito. A formação de textura poligonal entre hornblenda e plagioclásio sugere uma temperatura mínima de equilíbrio em torno de $600{ }^{\circ} \mathrm{C}$ (Passchier \& Trouw, 2005).

\subsection{Geoquímica de rocha total}

Os resultados degeoquímica derochatotal obtidos para a amostra PU-45 são apresentados na tabela 1. Os óxidos de elementos maiores são expressos em porcentagem-peso $\left(\%_{\text {peso }}\right)$, e os elementos traços e ETR em partes por milhão (ppm). O ferro total é expresso em $\mathrm{Fe}_{2} \mathrm{O}_{3}$.

Para medir o grau de alteração intempérica da amostra foram usados os índices de alteração química $\left(\mathrm{ClA}=\left[\mathrm{Al}_{2} \mathrm{O}_{3} / \mathrm{Al}_{2} \mathrm{O}_{3}+\mathrm{CaO}\right.\right.$ $\left.+\mathrm{Na}_{2} \mathrm{O}+\mathrm{K}_{2} \mathrm{O}\right]$ * 100 molar) e de alteração de plagioclásio ( $\mathrm{PIA}=\left[\mathrm{Al}_{2} \mathrm{O}_{3}-\mathrm{K}_{2} \mathrm{O}\right] /\left[\mathrm{Al}_{2} \mathrm{O}_{3}+\mathrm{CaO}\right.$ $\left.+\mathrm{Na}_{2} \mathrm{O}-\mathrm{K}_{2} \mathrm{O}\right] * 100$ molar), respectivamente de Nesbitt \& Young (1982) e Fedo et al. (1995). Para os valores recalculados de $\mathrm{Al}_{2} \mathrm{O}_{3}=0,18, \mathrm{CaO}=$ $0,14, \mathrm{Na}_{2} \mathrm{O}=0,06$, e $\mathrm{K}_{2} \mathrm{O}=0,02$ (molar), o índice CIA encontrado foi de 45, dentro do espectro dos basaltoides inalterados (30 a 45; Nesbitt \& Young, 1982). Juntamente com o índice PIA encontrado, de 44, ambos os índices indicam que a amostra é pouco alterada (Fedo et al., 1995).

As concentrações de óxidos de elementos maiores da amostra são, em geral, compatíveis com a média dos basaltos oceânicos de Gale et al. (2013) e também com a média da porção máfica da crosta continental inferior (Hacker et al., 2015). São observadas concentrações 1 a $2 \%$ mais elevadas de $\mathrm{Al}_{2} \mathrm{O}_{3^{\prime}}, \mathrm{FeO}_{\text {total }}$ e $\mathrm{K}_{2} \mathrm{O}$, e 1 a $2 \%$ menos elevadas de $\mathrm{MgO}$ e $\mathrm{CaO}$, as quais podem refletir o enriquecimento em biotita e os processos secundários de epidotização observados em microscopia óptica (seção 4.1).

O Índice de Diferenciação (Thornton \& Tuttle, 1960) da amostra, no valor de 44, calculado a partir da mineralogia normativa (Tab. 1), sugere uma composição gabroica (30) a diorítica (48). No diagrama de álcalis total versus sílica (TAS; Cox et al., 1979) a amostra plota no campo dos gabros (Fig. 4A).

Uma vez que não há evidências petrográficas de processos cumuláticos e a amostra apresenta composição próxima a de basaltos, assume-se que o protólito da amostra é um gabro de origem não-cumulática (e.g., Yamasaki \& Nanayama, 2017). Dessa maneira, as discussões geoquímicas desta e das próximas seções consideram a amostra como uma rocha magmática, ou seja, seu protólito gabroico, uma vez que as concentrações dos elementos maiores foram pouco modificadas por processos metamórficos e de alteração. 

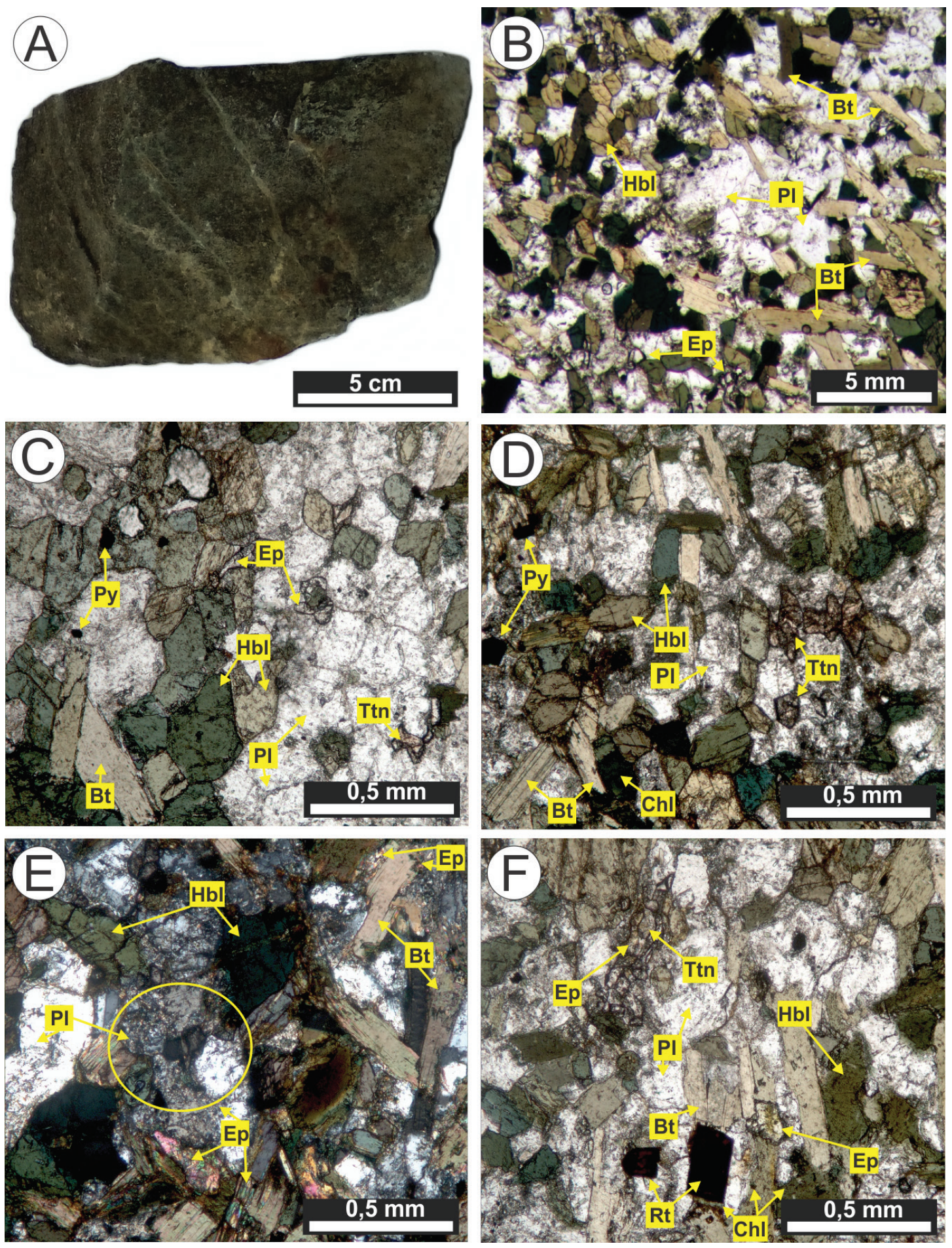

Figura 3. Aspectos petrográficos do Anfibolito Alto Alegre, amostra PU-45. A) Amostra de mão, mostrando estrutura predominantemente maciça com foliação incipiente e composição predominantemente máfica; B) Textura (microestrutura) granoblástica marcada por cristais poligonais de hornblenda e plagioclásio (nicóis descruzados, magnificação de 2,5x); C) e D) Regiões da lâmina onde é possível identificar foliação marcada pela orientação preferencial de hornblenda, plagioclásio, epidoto, titanita e biotita (nicóis descruzados, magnificação de 5x); E) Epidotização de plagioclásio e biotita. Círculo amarelo marca zona de intensa saussuritização (nicóis cruzados, magnificação de 5x); F) Formação de clorita, epidoto e rutilo a expensas de biotita (nicóis descruzados, magnificação de 5x). Abreviações (Whitney \& Evans, 2010): Bt = biotita; $\mathrm{Chl}=$ clorita; $\mathrm{Ep}=$ epidoto; $\mathrm{Hbl}=$ hornblenda; $\mathrm{Pl}=$ plagioclásio; $\mathrm{Py}=$ pirita; $\mathrm{Rt}=$ rutilo; Ttn = titanita .

Figure 3. Petrographic characteristics of the studied amphibolite. A) Hand sample, showing the massive, slightly foliated structure, and predominance of mafic components; B) Granoblastic microstructure marked by polygonal hornblende and plagioclase (uncrossed polars, 2.5x magnification); $C$ ) and D) Regions of the thin section where it is possible to observe a foliation marked by the preferred orientation of hornblende, plagioclase, epidote, and biotite (uncrossed polars, $5 x$ magnification); E) Epidotization of plagioclase and biotite. The yellow circle marks a zone with intense saussuritization (crossed polars, 5x magnification); F) Formation of chlorite, epidote, and rutile at the expense of biotite (uncrossed polars, $5 x$ magnification). Abbreviations (Whitney \& Evans, 2010): Bt = biotite; $\mathrm{Chl}=$ chlorite; $\mathrm{Ep}=$ epidote; $\mathrm{Hbl}=$ hornblende; $\mathrm{Pl}=$ plagioclase; $P y=$ pyrite; $R t=$ rutile; $T$ tn = titanite . 
Tabela 1. Composição química (rocha total) da amostra PU-45. * = ferro total expresso em $\mathrm{Fe}_{2} \mathrm{O}_{3}$. LOI = perda ao fogo. **Minerais normativos (Cox et al., 1979). ${ }^{\text {a }}=$ média da composição dos anfibolitos Pinheiro Machado (APM), anfibolitos Arroio Grande (AAG) e metagabros Arroio Grande (MAG), compilado de Ramos \& Koester (2015).

Table 1. Chemical composition (whole rock) of sample $\mathrm{PU}-45$. * = Total iron as $\mathrm{Fe}_{2} \mathrm{O}_{3}$. LOI = loss on ignition. **Normative minerals (Cox et al., 1979). ${ }^{a}=$ average composition of the Pinheiro Machado amphibolites (APM), Arroio Grande amphibolites (AAG) and Arroio Grande metagabbros (MAG), compiled from Ramos \& Koester (2015).

\begin{tabular}{|c|c|c|c|c|}
\hline Amostra & PU-45 & $\mathrm{APM}^{\mathrm{a}}$ & $\mathrm{AAG}^{\mathrm{a}}$ & $\mathrm{MAG}^{\mathrm{a}}$ \\
\hline $\mathrm{SiO}_{2}$ & 48,15 & 48,53 & 49,38 & 49,12 \\
\hline $\mathrm{Al}_{2} \mathrm{O}_{3}$ & 18,27 & 15,08 & 15,18 & 14,88 \\
\hline $\mathrm{K}_{2} \mathrm{O}$ & 1,99 & 2,06 & 1,37 & 1,52 \\
\hline $\mathrm{CaO}$ & 7,89 & 8,61 & 10,20 & 8,92 \\
\hline $\mathrm{Fe}_{2} \mathrm{O}_{3}{ }^{*}$ & 11,30 & 11,24 & 10,76 & 11,06 \\
\hline $\mathrm{MgO}$ & 4,59 & 8,01 & 7,00 & 8,12 \\
\hline $\mathrm{MnO}$ & 0,22 & 0,19 & 0,17 & 0,14 \\
\hline $\mathrm{Na}_{2} \mathrm{O}$ & 3,78 & 2,81 & 2,03 & 1,97 \\
\hline $\mathrm{TiO}_{2}$ & 1,42 & 1,22 & 1,15 & 1,16 \\
\hline $\mathrm{P}_{2} \mathrm{O}_{5}$ & 0,32 & 0,18 & 0,09 & 0,15 \\
\hline LOI & 1,82 & 1,75 & 2,36 & 2,60 \\
\hline $\mathrm{Ba}$ & 407 & 288 & 256 & 332 \\
\hline $\mathrm{Hf}$ & 4,5 & 3,6 & 2,2 & 2,9 \\
\hline $\mathrm{Nb}$ & 10,1 & 6,9 & 3,4 & 5,2 \\
\hline $\mathrm{Pb}$ & 4,3 & 2,0 & 0,6 & 1,7 \\
\hline $\mathrm{Rb}$ & 137 & 130 & 58 & 61 \\
\hline $\mathrm{Sr}$ & 612 & 427 & 132 & 515 \\
\hline $\mathrm{Ta}$ & 0,4 & 0,4 & 0,2 & 0,4 \\
\hline Th & 6,5 & 3,9 & 0,9 & 3,4 \\
\hline Y & 34,7 & 23,1 & 23,1 & 19,1 \\
\hline $\mathrm{Zr}$ & 172,7 & 111,3 & 81,5 & 105,1 \\
\hline $\mathrm{La}$ & 39,5 & 18,4 & 6,3 & 21,9 \\
\hline $\mathrm{Ce}$ & 80,4 & 45,2 & 13,4 & 45,8 \\
\hline $\operatorname{Pr}$ & 11,72 & 6,04 & 2,04 & 5,46 \\
\hline $\mathrm{Nd}$ & 49,1 & 26,7 & 10,0 & 22,6 \\
\hline $\mathrm{Sm}$ & 9,65 & 6,01 & 2,80 & 4,49 \\
\hline $\mathrm{Eu}$ & 2,40 & 1,61 & 0,99 & 1,22 \\
\hline $\mathrm{Gd}$ & 8,5 & 5,78 & 3,55 & 4,1 \\
\hline $\mathrm{Tb}$ & 1,20 & 0,74 & 0,62 & 0,59 \\
\hline Dy & 6,21 & 4,84 & 4,29 & 3,53 \\
\hline Но & 1,25 & 0,80 & 0,84 & 0,71 \\
\hline Er & 3,38 & 2,23 & 2,79 & 1,94 \\
\hline $\mathrm{Tm}$ & 0,44 & 0,32 & 0,38 & 0,29 \\
\hline $\mathrm{Yb}$ & 2,68 & 2,05 & 2,35 & 1,75 \\
\hline $\mathrm{Lu}$ & 0,42 & 0,31 & 0,37 & 0,25 \\
\hline
\end{tabular}

**Composição normativa CIPW da amostra PU-45: $Q=0,000 ;$ Or $=11,760 ; A b=31,985 ; A n=$ 27,006; $\mathrm{Di}=4,642 ; \mathrm{Hy}=2,178 ; \mathrm{Ol}=4,979 ; \mathrm{Il}=0,471 ; \mathrm{Hm}=11,301 ; \mathrm{Tn}=2,878 ; \mathrm{Pf}=0,000 ; \mathrm{Ap}=$ 0,758 
As concentrações de elementos traços da amostra sugerem um componente de contaminação crustal, a partir dos elevados teores de elementos móveis como, por exemplo, $\mathrm{Ba}$ (407 ppm), Rb (137 ppm) e Sr (612 ppm). Esse componente é também sugerido pelos diagramas multielementares de elementos traços e ETR (Fig. 4B e 4C) normalizados, respectivamente, ao condrito (Thompson, 1982) e ao manto primitivo (McDonough \& Sun, 1995). Nesses diagramas se observa enriquecimento em elementos litófilos de íon grande (LILE) em relação a elementos de alto campo de força (HFSE) (Fig. 4B) e de ETR leves em relação aos médios e aos pesados (Fig. 4C). A contaminação crustal poderia estar relacionada tanto à fonte quanto ao fato de a amostra ser um xenólito em granitoide. Uma terceira hipótese poderia ser uma contaminação da fonte basáltica por fluidos e/ou sedimentos relacionados à subducção, considerando que a assinatura da amostra apresenta elevadas concentrações de LILE em relação a HFSE e anomalias negativas de Nb e Ta (Fig. 4B) (e.g., Pearce et al., 1984).

A partir de elementos traços e ETR menos móveis, algumas considerações em relação a ambientes tectônicos podem ser levantadas. No diagrama de $V$ versus Ti (Shervais, 1982) a amostra plota no campo dos basaltos MORB e BABB (Fig. 4D). No diagrama de razões $\mathrm{Nb} / \mathrm{Y}$ versus Ti/Y (Pearce, 1982) a amostra plota no campo dos basaltos MORB(Fig. 4E). Essa hipótese é fortalecida pelo diagrama de razões Ti/Y versus Zr/Y (Pearce \& Gale, 1977) apresentado na figura $4 \mathrm{~F}$, onde a amostra plota no campo dos basaltos de margem de placa, e também pelos diagramas apresentados nas figuras 4G (funções baseadas em razões de $\mathrm{Sm} / \mathrm{Th}$, Yb/Th e Nb/Th, de Agrawal et al., 2008) e 4H (diagrama ternário Nb-Zr-Y, de Meschede, 1986), onde a amostra plota no campo dos IAB.

A alta razão $\mathrm{Ce} / \mathrm{Pb}=18$, e a razão $\mathrm{Pb} / \mathrm{Ce}$ $=0,05$, sugerem uma afinidade com basaltos tipo MORB (Plank, 2005; Porter \& White, 2003; Rollinson, 2007), reforçada pela razão $\mathrm{Sr} / \mathrm{Nd}=12$ (McDonough \& McCulloch, 1987). A razão Th/La = 0,16 fortalece a hipótese, apontando para uma afinidade com basaltos oceânicos (Plank, 2005). A razão $\mathrm{La} / \mathrm{Nb}=3,9$ aponta para uma afinidade com basaltos de arco (Plank, 2005). Essas razões de elementos traços demonstram que, apesar das concentrações de óxidos de elementos maiores serem similares tanto a basaltos oceânicos quanto de crosta continental inferior, a amostra tem assinatura oceânica (Hacker et al., 2015).

A assinatura oceânica da amostra varia entre MORB e IAB. Essa característica aponta para uma possível fonte relacionada a ambientes de suprassubducção (Pearce et al., 1984), i.e., relacionados à expansão de assoalho oceânico em margem ativa acima de litosfera oceânica subductada. Na zona de suprassubducção está englobado tanto o antearco, o retroarco, como o próprio arco insular. Na região do retroarco, o assoalho oceânico gerado apresenta assinatura geoquímica similar, ou até mesmo idêntica, ao MORB (e.g., Pearce et al., 1984; Hawkins, 2003).

\subsection{Geoquímica isotópica ( $\mathrm{Sr}-\mathrm{Nd}$ )}

Para o presente estudo foi usada a idade de 630 Ma como referência para o recálculo dos resultados obtidos nas análises isotópicas (Tab. 2). Essa idade é a mais antiga atribuída a granitoides da suíte intrusiva Pinheiro Machado (ver seção 2.1) e, como a amostra estudada é um xenólito nesses granitoides, a idade de sua extração do manto é anterior. O cálculo da idademodelo $\left(T_{D M}\right)$ foi realizado com o modelo de dois estágios, considerando que a amostra passou por processos pós-magmáticos como, por exemplo, o metamorfismo de fácies anfibolito (ver seção 4.1).

As razões ${ }^{87} \mathrm{Sr} /{ }^{86} \mathrm{Sr}_{(\mathrm{t})}=0,707 \mathrm{e}^{147} \mathrm{Sm} /{ }^{144} \mathrm{Nd}=$ 0,118 da amostra sugerem uma fonte mantélica contaminada por componentes crustais. Usando a notação épsilon de neodímio (DePaolo \& Wasserburg, 1976), a amostra estudada apresenta um valor negativo de $\varepsilon \mathrm{d}_{(\mathrm{t})}=-7,5$, reforçando a hipótese de uma fonte contaminada, em algum momento de sua evolução, por componentes crustais (DePaolo \& Wasserburg, 1979). Tais valores também são compatíveis com a porção máfica da crosta continental inferior (Rollinson, 1993), porém, a assinatura geoquímica de rocha total (seção 4.2) aponta para uma fonte oceânica.

No diagrama de $\varepsilon$ Nd versus ${ }^{87} \mathrm{Sr} /{ }^{86} \mathrm{Sr}$ a amostra plota dentro do espectro composicional 

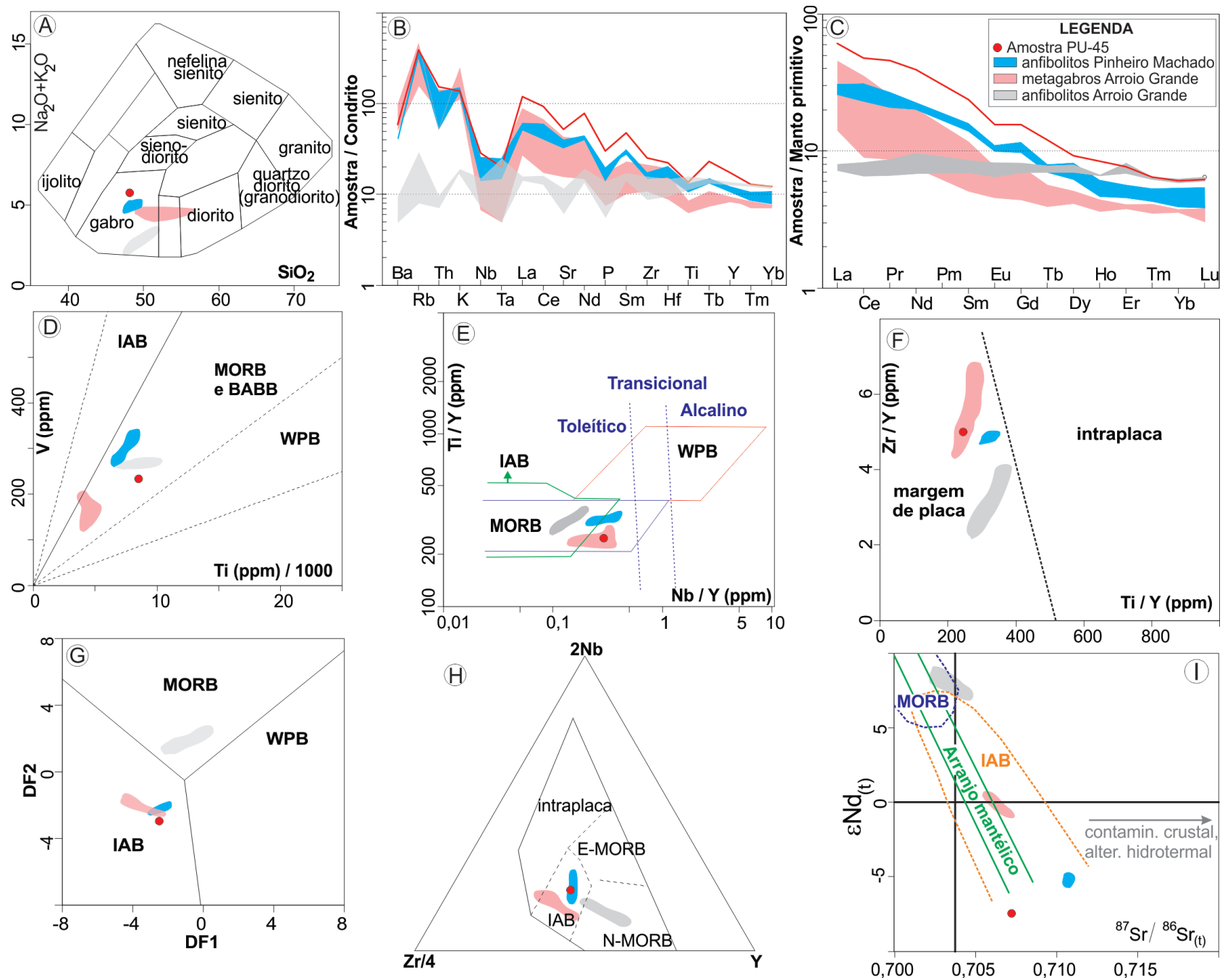

Figura 4. Diagramas de geoquímica de rocha total e isotópica. A) Diagrama de álcalis total versus sílica (TAS), modificado de Cox et al. (1979); B) Diagrama multielementar de traços e ETR, normalizado ao condrito de Thompson (1982); C) Diagrama multielementar de ETR, normalizado ao manto primitivo de McDonough \& Sun (1995); D) Diagrama discriminante Ti versus $\mathrm{V}$, modificado de Shervais (1982); E) Diagrama discriminante $\mathrm{Nb} / \mathrm{Y}$ versus Ti/Y, modificado de Pearce (1982); F) Diagrama discriminante $\mathrm{Ti} / \mathrm{Y}$ versus $\mathrm{Zr} / \mathrm{Y}$, modificado de Pearce \& Gale (1977); G) Diagrama discriminante usando as funções DF1 (1,7517 $\left.\log _{e}[\mathrm{Sm} / \mathrm{Th}]-1,9508 \log _{\mathrm{e}}[\mathrm{Yb} / \mathrm{Th}]+1,9573 \log _{\mathrm{e}}[\mathrm{Nb} / \mathrm{Th}]-5,0928\right)$ e DF2 (- 2,2412 log $[\mathrm{Sm} /$ $\left.\mathrm{Th}]+2,2060 \log _{\mathrm{e}}[\mathrm{Yb} / \mathrm{Th}]+1,2481 \log _{\mathrm{e}}[\mathrm{Nb} / \mathrm{Th}]-0,8243\right)$, modificado de Agrawal et al. (2008); H) Diagrama ternário discriminante $\mathrm{Nb}-\mathrm{Zr}-\mathrm{Y}$, modificado de Meschede (1986); I) Diagrama $\varepsilon N d$ versus ${ }^{87} \mathrm{Sr} /{ }^{86} \mathrm{Sr}$, modificado de DePaolo \& Wasserburg (1979). Campos MORB e IAB de Wilson (1989).

Figure 4. Whole rock and isotope geochemistry diagrams. A) Total alkalis versus silica diagram (TAS), modified from Cox et al. (1979); B) Chondrite-normalized (Thompson, 1982) multi-element trace and REE diagram; C) Primitive mantlenormalized (McDonough \& Sun, 1995) multi-element REE diagram; D) Ti versus $V$ discrimination diagram, modified from Shervais (1982); E) Nb/Y versus Ti/Y discrimination diagram, modified from Pearce (1982); $F$ ) $T i / Y$ versus $\mathrm{Zr} / \mathrm{Y}$ discrimination diagram, modified from Pearce \& Gale (1977); G) DF1 (1,7517 loge [Sm/Th] - 1,9508 $\log _{\mathrm{e}}[\mathrm{Yb} / \mathrm{Th}]+1,9573$ $\left.\log _{\mathrm{e}}[\mathrm{Nb} / \mathrm{Th}]-5,0928\right)$ versus DF2 (-2,2412 $\left.\log _{\mathrm{e}}[\mathrm{Sm} / \mathrm{Th}]+2,2060 \log _{\mathrm{e}}[\mathrm{Yb} / \mathrm{Th}]+1,2481 \log _{\mathrm{e}}[\mathrm{Nb} / \mathrm{Th}]-0,8243\right)$ discrimination diagram, modified from Agrawal et al. (2008); H) Nb-Zr-Y discrimination diagram, modified from Meschede (1986); I) $\varepsilon N d$ versus ${ }^{87} \mathrm{Sr} /{ }^{86} \mathrm{Sr}$ diagram, modified from DePaolo \& Wasserburg (1979). MORB and IAB fields from Wilson (1989). 
Tabela 2. Resultados de geoquímica isotópica (sistemas $\mathrm{Rb}-\mathrm{Sr}$ e $\mathrm{Sm}-\mathrm{Nd}$ ) para a amostra PU-45. Table 2. Isotope geochemistry results ( $\mathrm{Rb}-\mathrm{Sr}$ and $\mathrm{Sm}-\mathrm{Nd}$ systems) for sample PU-45.

\begin{tabular}{|c|c|c|c|c|c|c|c|c|c|}
\hline $\begin{array}{c}\mathrm{Sm} \\
(\mathrm{ppm})\end{array}$ & $\begin{array}{c}\mathrm{Nd} \\
(\mathrm{ppm})\end{array}$ & $\mathrm{Sm} / \mathrm{Nd}$ & $\begin{array}{c}{ }^{143} \mathrm{Nd} /{ }^{144} \mathrm{Nd} \\
\text { medido }\end{array}$ & $\begin{array}{c}{ }^{147} \mathrm{Sm} /{ }^{144} \mathrm{Nd} \\
\text { calculado }\end{array}$ & $\begin{array}{c}\text { Idade } \\
\text { assumid } \\
\text { a (t) }\end{array}$ & $\begin{array}{c}{ }^{143} \mathrm{Nd} /{ }^{144} \mathrm{Nd} \\
\text { (t) }\end{array}$ & $\begin{array}{c}\varepsilon N d \\
(\mathrm{t})\end{array}$ & $\begin{array}{l}\mathrm{T}_{\mathrm{DM}} \\
(\mathrm{Ga})\end{array}$ & $\begin{array}{c}\text { Erro } \\
\text { padrão } \\
(\%)\end{array}$ \\
\hline 9,65 & 49,1 & 0,196 & 0,511920 & 0,118498 & $630 \mathrm{Ma}$ & \multirow[t]{3}{*}{0,511415} & \multirow[t]{3}{*}{$-7,5$} & \multirow[t]{3}{*}{1,9} & $\begin{array}{c}0,08519 \\
7\end{array}$ \\
\hline $\begin{array}{c}\mathrm{Rb} \\
(\mathrm{ppm})\end{array}$ & $\begin{array}{c}\mathrm{Sr} \\
(\mathrm{ppm})\end{array}$ & $\begin{array}{c}{ }^{87} \mathrm{Sr} /{ }^{86} \mathrm{Sr} \\
\text { medido }\end{array}$ & $\begin{array}{c}\text { Idade } \\
\text { assumida } \\
\text { (t) }\end{array}$ & $\begin{array}{c}{ }^{87} \mathrm{Sr} /{ }^{86} \mathrm{Sr} \\
(\mathrm{t})\end{array}$ & $\begin{array}{c}\text { Erro } \\
\text { padrão } \\
(\%)\end{array}$ & & & & \\
\hline 137 & 612 & $\begin{array}{c}0,71323 \\
77 \\
\end{array}$ & $630 \mathrm{Ma}$ & 0,707227 & 0,0025 & & & & \\
\hline
\end{tabular}

dos basaltos de arco insular (Fig. 4I). Isso fortalece a hipótese de uma fonte relacionada a ambiente de suprassubducção (Bulle et al., 2010; Bröcker et al., 2014) (ver seção 4.2).

Dessa maneira, a componente crustal observada na assinatura geoquímica e isotópica da amostra pode estar relacionada às mesmas hipóteses levantadas na seção 4.2, isto é, a sua fonte pode ter sido contaminada porcomponentes crustais, inclusive relacionados à subducção, ou o magma pode ter assimilado componentes crustais durante a sua ascensão. Ainda, deve ser considerado o fato de que a amostra é um xenólito, de maneira que a granitogênese da encaixante - a qual apresenta geoquímica com assinatura de arco magmático continental relacionado à subducção (e.g., Fernandes et al., 1995a; Silva, 1999, 2005b) - pode estar relacionada também a essa contaminação. Como consequência, o valor de $T_{D M}$ de 1,9 Ga não representa uma idade de extração do manto, mas a mistura desta última com componentes crustais mais antigos.

\subsection{Comparação com outras unidades do extremo sul do Escudo sul-rio-grandense}

Nesta seção a amostra PU-45 é comparada com unidades metamáficas do extremo sul do Escudo Sul-rio-grandense que são mais antigas que os granitoides da suíte intrusiva Pinheiro Machado, uma vez que os Anfibolitos Alto Alegre são encontrados como xenólitos nestes. Devido à assinatura oceânica da amostra, demonstrada anteriormente, foram selecionadas para a comparação unidades que também apresentam assinatura geoquímica oceânica: anfibolitos (metagabros) encontrados como xenólitos em granitoides da suíte intrusiva Pinheiro Machado, localizados na região de Monte Bonito, a nordeste de Herval (Ramos \& Koester, 2015; Loureiro et al., 2015); e anfibolitos e metagabros do Ofiolito Arroio Grande (Ramos \& Koester, 2015; Ramos et al., 2018; Ramos et al., 2020), localizados a sudeste.

Apesar de ser enriquecida em torno de 20 vezes em relação aos anfibolitos de Monte Bonito, e cerca de 30 vezes em relação aos metagabros de Arroio Grande, os padrões de elementos traços e ETR (Fig. 4B e 4C) são similares, sugerindo uma fonte em comum. Em todos os diagramas geoquímicos discriminantes apresentados na figura 4, todas as unidades acima plotam nos mesmos campos.

As suas razões de elementos traços são também similares (média dos anfibolitos de Monte Bonito: $\mathrm{Ce} / \mathrm{Pb}=24 ; \mathrm{Pb} / \mathrm{Ce}=0,04 ; \mathrm{Sr} /$ $\mathrm{Nd}=$ 9,6; Th/La = 0,11; La/Nb = 2,6; média dos metagabros do Ofiolito Arroio Grande: $\mathrm{Ce} / \mathrm{Pb}=$ 26; $\mathrm{Pb} / \mathrm{Ce}=0,04 ; \mathrm{Sr} / \mathrm{Nd}=23 ; \mathrm{Th} / \mathrm{La}=0,4 ; \mathrm{La} / \mathrm{Nb}$ = 1,3; Ramos \& Koester, 2015), sugerindo uma fonte oceânica similar, relacionada a ambiente de suprassubducção, com componentes de contaminação crustal. Essa hipótese é reforçada pelas assinaturas isotópicas (Fig. 4l), sendo os metagabros Arroio Grande os que apresentam menor contaminação, enquanto os anfibolitos Monte Bonito, maior.

Diferentemente das unidades acima mencionadas, os anfibolitos do Ofiolito Arroio Grande apresentam assinatura geoquímica e isotópica tipicamente MORB (Fig. 4B a 4I), representando as rochas com menor ou nenhuma contaminação crustal do Ofiolito Arroio Grande. Trabalhos anteriores (Ramos \& Koester, 
2015; Ramos et al., 2017, 2018, 2020) levantaram a hipótese de que os protólitos dos anfibolitos e dos metagabros foram gerados em ambiente de retroarco.

Ramos \& Koester (2015) sugeriram que os anfibolitos de Monte Bonito também poderiam ter sido gerados no mesmo ambiente de retroarco, representando fragmentos da mesma bacia oceânica. Todas essas unidades foram inseridas em um modelo que envolve a abertura do paleooceano Adamastor Sul, em um ambiente de retroarco em torno de $750 \mathrm{Ma}$ (Ramos et al., 2017, 2018, 2020). Por volta de 650 Ma teve início o fechamento dessa bacia, com a geração de um arco magmático continental na nova margem ativa, representado pelos granitoides da suíte intrusiva Pinheiro Machado (Ramos et al., 2017, 2018, 2020). Durante a evolução desse arco, fragmentos da crosta oceânica foram capturados, representados pelos xenólitos de anfibolitos de Monte Bonito e pelos Anfibolitos Alto Alegre.

Embora até o momento não existam dados geocronológicos dos Anfibolitos Alto Alegre para corroborar ou refutar o modelo de evolução mencionado acima, sua assinatura geoquímica e isotópica permite assumir uma origem oceânica para o protólito da amostra estudada. Uma vez que a idade mais jovem para granitoides da suíte intrusiva Pinheiro Machado giram em torno de 618 Ma (e.g., Loureiro et al., 2015), tanto os anfibolitos de Monte Bonito como os Anfibolitos Alto Alegre podem representar fragmentos de crosta oceânica gerada em um ambiente de suprassubducção, mais antigo que $618 \mathrm{Ma}$.

\section{Conclusões}

Os resultados obtidos a partir da amostra representativa dos Anfibolitos Alto Alegre demonstram que o protólito dessa unidade é um gabro. Esse gabro foi metamorfizado (metamorfismo orogênico) em condições de fácies anfibolito, com equilíbrio mínimo em ca. $600^{\circ} \mathrm{C}$.

As assinaturas geoquímicas e isotópicas do protólito gabroico sugerem um ambiente oceânico para a sua gênese, possivelmente relacionado à suprassubducção. Sua fonte mantélica foi provavelmente contaminada por fluidos e/ou sedimentos relacionados à subducção.

Uma vez que os Anfibolitos Alto Alegre são xenólitos em granitoides de arco magmático continental relacionado à subducção (suíte intrusiva Pinheiro Machado), é possível que, durante a evolução deste arco, fragmentos de crosta oceânica foram capturados pelo magma. Essa crosta oceânica pode ser representada pelos Anfibolitos Alto Alegre e também por outros xenólitos básicos, com assinatura geoquímica oceânica, encontrados no extremo sul do Escudo Sul-rio-grandense, podendo representar relictos do paleo-oceano Adamastor Sul.

Agradecimentos. Aos Editores, Prof. Dr. Carlos Augusto Sommer e Prof. Dr. Paulo Alves de Souza, pelo manejo editorial; aos dois revisores anônimos pelos comentários e sugestões construtivas que auxiliaram na melhoria do manuscrito; Fundação de Amparo à Pesquisa do Estado do Rio Grande do Sul (processo PqG 10/1509-0) e Conselho Nacional de Desenvolvimento Científico e Tecnológico (processo PQ 305853/2010-4) pelo financiamento do projeto de pesquisa coordenado pelo Prof. Dr. Edinei Koester.

\section{Referências}

Agrawal, S., Guevara, M. \& Verma, S.P. 2008. Tectonic discrimination of basic and ultrabasic volcanic rocks through log-transformed ratios of immobile trace elements. International Geology Review, 50(12): 1057-1079.

Almeida, F.F.M., Hasui, Y., Brito-Neves, B.B. \& Fuck, R.A., 1981. Brazilian structural provinces: an introduction. Earth Science Review, 17: 1-29.

Babinski M., Chemale Jr. F., Van Schmus W.R., Hartmann L.A. \& Silva L.C. 1997. U-Pb and Sm-Nd geochronology of the Neoproterozoic Granitic-Gneissic Dom Feliciano Belt, Southern Brazil. Journal of South American Earth Sciences, 10(3-4): 263-274.

Blanco, G., Germs, G.J.B., Rajesh, H.M., Chemale, F, Dussin, I.A. \& Justino, D. 2011. Provenance and paleogeography of the Nama Group (Ediacaran to early Palaeozoic, Namibia): petrography, geochemistry and $\mathrm{U}-\mathrm{Pb}$ detrital zircon geochronology. Precambrian Research, 187: 15-32. 
Bossi, J. \& Gaucher, C. 2004. The Cuchilla Dionisio Terrane, Uruguay: an allochthonous block accreted in the Cambrian to SW-Gondwana. Gondwana Research, 7(3): 661-674.

Brito-Neves, B.B., Fuck, R.A. \& Pimentel, M.M. 2014. The Brasiliano collage in South America: a review. Brazilian Journal of Geology, 44(3): 493-518.

Bröcker, M., Löwena, K. \& Rodionov, N. 2014. Unraveling protolith ages of meta-gabbros from Samos and the Attic-Cycladic Crystalline Belt, Greece: results of a U-Pb zircon and SrNd whole rock study. Lithos, 198/199: 234248.

Bulle, F., Bröcker, M., Gärtner, C. \& Keasling, A. 2010. Geochemistry and geochronology of HP mélanges from tinos and andros, cycladic blueschist belt, Greece. Lithos, 117: 61-81.

Chemale Jr., F., Hartmann, L.A. \& Silva, L.C. 1995.

Stratigraphy and tectonism of the Brasiliano Cycle in southern Brazil. Communications of the Geological Survey of Namibia, 10: 153168.

Costa, A.F.U. 1997. Teste e modelagem geofísica da estruturação das associações litotectônicas pré-cambrianas no Escudo Sul-rio-grandense. Porto Alegre, 291p. Tese de Doutorado, Programa de Pós-Graduação em Geociências, Instituto de Geociências, Universidade Federal do Rio Grande do Sul.

Cox, K.G., Bell, J.D. \& Pankhurst, R.J. 1979. The interpretation of igneous rocks. Londres, George, Allen and Unwin, 450 p.

DePaolo, D.J. \& Wasserburg, G.J. 1976. Nd isotopic variations and petrogenetic models. Geophysical Research Letters, 3: 249-252.

DePaolo, D.J. \& Wasserburg, G.J. 1979. Petrogenetic mixing models and $\mathrm{Nd}$-Sr isotopic patterns. Geochimica et Cosmochimica Acta, 43: 615-627.

Fedo, C.M., Nesbitt, H.W. \& Young, G.M. 1995. Unraveling the effects of potassium metasomatism in sedimentary rocks and paleosols, with implications for paleoweathering conditions and provenance. Geology, 23(10): 921-924.

Fernandes, L.A.D., Menegat, R., Costa, A.F.U., Koester, E., Porcher, C.C., Tommasi, A., Kraemer, G., Ramgrab, G.R. \& Camozzato, E. 1995a. Evolução tectônica do Cinturão Dom Feliciano no Escudo Sul-riograndense: Parte I - Uma contribuição a partir do registro geológico. Revista Brasileira de Geociências, 25(4): 351-374.

Fernandes, L.A.D., Menegat, R., Costa, A.F.U., Koester, E., Porcher, C.C., Tommasi, A., Kraemer, G., Ramgrab, G.R. \& Camozzato, E. 1995b. Evolução tectônica do Cinturão Dom Feliciano no Escudo Sul-riograndense: Parte II - Uma contribuição a partir das assinaturas geofísicas. Revista Brasileira de Geociências, 25(4): 375-384.

Fragoso-César, A.R.S. 1991. Tectônica de placas no Ciclo Brasiliano: as orogenias dos cinturões Dom Feliciano e Ribeira no Rio Grande do Sul. São Paulo, 367p. Tese de Doutorado, Programa de Pós-Graduação em Geoquímica e Geotectônica, Instituto de Geociências, Universidade de São Paulo.

Fragoso-César, A.R.S., Figueiredo, M.C.H., Soliani, E. \& Faccini, U.F. 1986. O Batólito Pelotas (Proterozóico Superior/Eo-Paleozóico) no Escudo do Rio Grande do Sul. In: CONGRESSO BRASILEIRO DE GEOLOGIA, 34, 1986, Goiânia. Anais... Goiânia, SBG, v. 3, p. 1322-1343.

Frantz, J.C. \& Nardi, L.V.S. 1992. Litogeoquímica e evolução dos granitóides cálcio-alcalinos da região leste do Escudo Sul-rio-grandense. Pesquisas, 19: 13-25.

Gale, A., Dalton, C.A., Langmuir, C.H., Su, Y. \& Schilling, J.G. 2013. The mean composition of ocean ridge basalts. Geochemistry, Geophysics, Geosystems, 14(3): 489-518.

Gaucher, C., Sial, A., Halverson, G. \& Frimmel, H. (Eds.). 2009. Neoproterozoic-Cambrian tectonics, global change and evolution: a focus on South Western Gondwana. Developments in Precambrian Geology, v. 16, 498p.

Gray, D.R., Foster, D.A., Meert, J.G., Goscombe, B.D., Armstrong, R., Trouw, R.A.J. \& Passchier, C.W. 2008. A Damara orogen perspective on the assembly of southwestern Gondwana. In: Pankhurst, R.J., Trouw, R.A.J., Brito-Neves, B.B. \& De Wit, M.J. (Eds.). West Gondwana: Pre-Cenozoic correlations across the South Atlantic Region. Geological Society of London, Special Publication, 294, p. 257-278.

Hacker, B. R., Kelemen, P. B. \& Behn, M. D. 2015. 
Continental Lower Crust. Annual Review of Earth and Planetary Sciences, 43(1): 167-205. Hartmann, L.A., Chemale Jr., F. \& Philipp, R.P. 2007. Evolução geotectônica do Rio Grande do Sul no Pré-Cambriano. In: Iannuzzi, R. \& Frantz, J.C. (Eds.). 50 Anos de Geologia: Instituto de Geociências. Contribuições. Porto Alegre, Comunicação e Identidade, p. 97-123. Hawkins, J.W. 2003. Geology of supra-subduction zones: implications for the origin of ophiolites. In: Dilek, Y. \& Newcomb, S. (Eds.). Ophiolite concept and the evolution of geological thought. Geological Society of America, Special Paper, 373, 227-268.

Hueck, M., Oyhantçabal, P., Philipp, R.P., Basei, M.A.S. \& Siegesmund, S. 2018. The Dom Feliciano Belt in southern Brazil and Uruguay. In: Siegesmund, S., Basei, M.A.S, Oyhantçabal, P. \& Oriolo, S. (Eds.). Geology of Southwest Gondwana. Springer, Regional Geology Review, pp. 267-302.

Janoušek, V., Farrow, C.M. \& Erban, V. 2006. Interpretation of whole-rock geochemical data in igneous geochemistry: introducing Geochemical Data Toolkit (GCDkit). Journal of Petrology, 47(6): 1255-1259.

Loureiro, P.O., Koester, E., Weinberg, R.F., Porcher, C.C., Pimentel, M.M. \& Knijnik, D. 2015. Magmatic evolution of Pinheiro Machado Complex in Monte Bonito region, Southern Brazil. In: HUTTON SYMPOSIUM ON GRANITES AND RELATED ROCKS, 8, 2015, Florianópolis. Anais... Florianópolis, SBG, p. 125.

McDonough, W.F. \& McCulloch, M.T. 1987. The southeast Australian lithospheric mantle: isotopic and geochemical constraints on its growth and evolution. Earth and Planetary Science Letters, 86: 327-340.

McDonough, W.F. \& Sun, S.S. 1995. The composition of the Earth. Chemical Geology, 120: 223-254.

Meschede, M. 1986. A method of discriminating between diferente types of mid-ocean ridge basalts and continental tholeiites with the $\mathrm{Nb}$ Zr-Y diagram. Chemical Geology, 56: 207-218. Nesbitt,H.W.\&Young, G.M. 1982. Early Proterozoic climates and plate motions inferred from major element chemistry of lutites. Nature, 299(5885): 715-717.
Passchier, C.W. \& Trouw, R.A.J. 2005. Microtectonics. Berlim, Springer, 366p.

Pearce, J.A. 1982. Trace element characteristics of lavas from destructive plate boundaries. In: Thorpe, R.S. (Ed.). Andesites. Chichester, Wiley, p. 525-548.

Pearce, J.A. \& Gale, G.H. 1977. Identification of ore-deposition environment from trace element geochemistry of associated igneous host rocks. Geological Society of London, Special Publication, v. 7, p. 14-24.

Pearce J.A., Lippard, S.J. \& Roberts, S. 1984. Characteristics and tectonic significance of supra-subduction zone ophiolites. In: Kokelaar, B.P. \& Howells, M.F. (Eds.). Marginal basin geology: volcanic and associated sedimentary and tectonic processes in modern and ancient marginal basins. Geological Society of London, Special Publications, v. 16, p. 77-94.

Philipp, R.P. 1998. A evolução geológica e tectônica do Batólito Pelotas no Rio Grande do Sul. São Paulo, 255p. Tese de Doutorado, Programa de Pós-Graduação em Geoquímica e Geotectônica, Instituto de Geociências, Universidade de São Paulo.

Philipp R.P. \& Machado, R. 2002. Ocorrência e significado dos septos do embasamento encontrados nas suítes graníticas do Batólito Pelotas, RS, Brasil. Pesquisas, 29(1): 43-57.

Philipp, R.P., Pimentel, M.M. \& Chemale Jr., F. 2016. Tectonic evolution of the Dom Feliciano Belt in Southern Brazil: geological relationships and $\mathrm{U}-\mathrm{Pb}$ geochronology. Brazilian Journal of Geology, 46(1): 83-104.

Plank, T. 2005. Constraints from Thorium/ Lanthanum on Sediment Recycling at Subduction Zones and the Evolution of the Continents. Journal of Petrology, 46(5): 921944.

Porter, K.A. \& White W. 2003. The deep mantle subduction flux and its implications for mantle Th/U and Pb/Ce ratios. São Francisco, American Geophysical Union, Fall Meeting Supplement Abstracts.

Ramos, R.C. \& Koester, E. 2014. Geologia da associação metamáfica-ultramáfica da região de Arroio Grande, sudeste do Escudo Sul-RioGrandense. Pesquisas em Geociências, 41(1): 25-38. 
Ramos, R.C. \& Koester, E. 2015. Lithogeochemistry of the meta-igneous units from Arroio Grande Ophiolitic Complex, southernmost Brazil. Brazilian Journal of Geology, 45(1): 65-78.

Ramos, R.C., Toniolo, J.A., Pinto, G.R. \& Koester, E. 2014. Zona de cisalhamento (sutura) de Arroio Grande e o novo Domínio Geofísico Sudeste (Escudo Sul-Rio-Grandense): discussões baseadas em dados geofísicos e de campo. In: SIMPÓSIO BRASILEIRO DE GEOFÍSICA, 6, 2014, Porto Alegre. Boletim de Resumos Expandidos...Porto Alegre, SBGf, 6p.

Ramos, R.C., Koester, E. \& Porcher, C.C. 2017. Chemistry of chromites from Arroio Grande Ophiolite (Dom Feliciano Belt, Brazil) and their possible connection with the Nama Group (Namibia). Journal of South American Earth Sciences, 80: 192-206.

Ramos, R.C., Koester, E., Vieira, D.T., Porcher, C.C., Gezatt, J.N. \& Silveira, R.L. 2018. Insights on the evolution of the Arroio Grande Ophiolite (Dom Feliciano Belt, Brazil) from Rb-Sr and SHRIMP U-Pb isotopic geochemistry. Journal of South American Earth Sciences, 86: 38-53.

Ramos, R.C., Koester, E. \& Vieira, D.T. 2019. Plagioclase-hornblende geothermobarometry of metamafites from the Arroio Grande Ophiolite, Dom Feliciano Belt, southernmost Brazil. Journal of South American Earth Sciences, 95: 102262.

Ramos, R.C., Koester, E. \& Vieira, D.T. 2020. $\mathrm{Sm}-\mathrm{Nd}$ systematics of metaultramaficmafic rocks from the Arroio Grande Ophiolite (Brazil): insights on the evolution of the South Adamastor paleo-ocean. Geoscience Frontiers, 11, 2287-2296.

Rollinson, H.R. 1993. Using geochemical data: evaluation, presentation, interpretation. Londres, Longman, 352p.

Rollinson, H.R. 2007. Early Earth systems: a geochemical approach. Nova Iorque, Blackwell, 296 p.

Saalmann, K., Gerdes, A., Lahaye, Y., Hartmann, L.A., Remus, M.V.D. \& Läufer, A. 2011. Multiple accretion at the eastern margin of the Rio de la Plata craton: the prolonged Brasiliano orogeny in southernmost Brazil. International Journal of Earth Sciences, 100: 355-378.

Shervais, J.W. 1982. Ti-V plots and the petrogenesis of modern and ophiolitic lavas. Earth and Planetary Science Letters, 59: 101118.

Siegesmund, S., Basei, M.A.S., Oyhantçabal, P. \& Oriolo, S. (Eds.). 2018. Geology of Southwest Gondwana. Springer, Regional Geology Reviews, 688p.

Silva, L.C. 1999. Geocronologia U-Pb SHRIMP e Sm-Nd na Província Mantiqueira meridional, no Cinturão Saldania (África do Sul) e a evolução do Ciclo Brasiliano/Pan-Africano. Porto Alegre, 243p. Tese de Doutorado, Programa de Pós-Graduação em Geociências, Instituto de Geociências, Universidade Federal do Rio Grande do Sul.

Silva, L.C., McNaughton, N.J., Armstrong, R., Hartmann, L.A. \& Fletcher, I.R. 2005a. The Neoproterozoic Mantiqueira Province and its African connections: a zircon-based $\mathrm{U}-\mathrm{Pb}$ geochronologic subdivision for the Brasiliano/ Pan-African systems of orogens. Precambrian Research, 136: 203-240.

Silva, L.C., McNaughton, N.J. \& Fletcher, I.R. 2005b. SHRIMP U-Pb zircon geochronology of Neoproterozoic crustal granitoids (Southern Brazil): A case for discrimination of emplacement and inherited ages. Lithos, 82: 503-525.

Thompson, R.N. 1982, British Tertiary volcanic province. Scottish Journal of Geology, 18: 49107.

Thornton, C.P. \& Tuttle, O.F. 1960. Chemistry of Igneous Rocks, Part 1, Differentiation Index. American Journal of Science, 258: 664-684.

Vieira, D.T. 2020. O Arco Piratini: implicações na evolução do Cinturão Dom Feliciano (Brasil-Uruguai). Porto Alegre, 149p. Tese de Doutorado, Programa de Pós-Graduação em Geociências, Instituto de Geociências, Universidade Federal do Rio Grande do Sul.

Vieira, D.T., Koester, E., Ramos, R.C. \& Porcher, C.C. 2019. Sr-Nd-Hf isotopic constraints and $\mathrm{U}-\mathrm{Pb}$ geochronology of the Arroio Pedrado Gneisses, Dom Feliciano Belt, Brazil: A $680 \mathrm{Ma}$ shoshonitic event in the final stages of The Piratini Arc evolution. Journal of South American Earth Sciences, 95: 102294.

Whitney, D.L. \& Evans, B.W. 2010. Abbreviations for names of rock-forming minerals. American 
Mineralogist, 95: 185-187.

Wilson, M. 1989. Igneous petrogenesis: a global tectonic approach. Dordrecht, Springer, 466p.

Yamasaki, T. \& Nanayama, F. 2017. Enriched mid-ocean ridge basalt-type geochemistry of basalts and gabbros from the Nikoro Group, Tokoro Belt, Hokkaido, Japan. Journal of Mineralogical and Petrological Sciences, 112(6): 311-323. 